\title{
Proteomic profile determination of autosomal aneuploidies by mass spectrometry on amniotic fluids
}

\author{
Alain Mange ${ }^{1,2,3}$, Caroline Desmetz ${ }^{1,2,3}$, Virginie Bellet ${ }^{3}$, Nicolas Molinari ${ }^{4}$, \\ Thierry Maudelonde $e^{1,2,3}$ and Jerome Solassol*1,2,3
}

\begin{abstract}
Address: ${ }^{1}$ University of Montpellier I, Montpellier, France, ${ }^{2} \mathrm{CHU}$ Montpellier, Hôpital Arnaud de Villeneuve, Department of Cellular Biology, Montpellier, France, ${ }^{3}$ CRLC Val d'Aurelle, Department of Clinical Oncoproteomic, Montpellier, France and ${ }^{4}$ IURC, Department of Biostatistic, Epidemiology and Clinical Research, Montpellier, France

Email: Alain Mange - alain.mange@univ-montp1.fr; Caroline Desmetz - caroline.desmetz@univ-montp1.fr;

Virginie Bellet - virginie.bellet@unilim.fr; Nicolas Molinari - molinari@iurc.montp.inserm.fr; Thierry Maudelonde - t-maudelonde@chumontpellier.fr; Jerome Solassol* - j-solassol@chu-montpellier.fr

* Corresponding author
\end{abstract}

Published: II January 2008

Proteome Science 2008, 6:1 doi:10.1186/1477-5956-6-1
Received: 3 October 2007

Accepted: II January 2008

This article is available from: http://www.proteomesci.com/content/6/I/I

(C) 2008 Mange et al; licensee BioMed Central Ltd.

This is an Open Access article distributed under the terms of the Creative Commons Attribution License (http://creativecommons.org/licenses/by/2.0), which permits unrestricted use, distribution, and reproduction in any medium, provided the original work is properly cited.

\begin{abstract}
Background: Prenatal diagnosis of chromosomal abnormalities by cytogenetic analysis is timeconsuming, expensive, and requires highly qualified technicians. Rapid diagnosis of aneuploidies followed by reassurance of women with normal results can be performed by molecular analysis of uncultured foetal cells. In the present study, we developed a proteomic fingerprinting approach coupled with a statistical classification method to improve diagnosis of aneuploidies, including trisomies 13 , 18, and 21, in amniotic fluid samples.
\end{abstract}

Results: The proteomic spectra obtained from 52 pregnant women were compiled, normalized, and mass peaks with mass-to-charge ratios between 2.5 and $50 \mathrm{kDa}$ identified. Peak information was combined together and analysed using univariate statistics. Among the 208 expressed protein peaks, 40 differed significantly between aneuploid and non aneuploid samples, with AUC diagnostic values ranging from $0.7 \mathrm{I}$ to $0.9 \mathrm{I}$. Hierarchical clustering, principal component analysis and support vector machine (SVM) analysis were performed. Two class predictor models were defined from the training set, which resulted in a prediction accuracy of $92.3 \%$ and $96.43 \%$, respectively. Using an external and independent validation set, diagnostic accuracies were maintained at $87.5 \%$ and $91.67 \%$, respectively.

Conclusion: This pilot study demonstrates the potential interest of protein expression signature in the identification of new potential biological markers that might be helpful for the rapid clinical management of high-risk pregnancies.

\section{Background}

Trisomies are the largest group of chromosome abnormalities. In particular, trisomies for chromosome 13 (Patau's syndrome), 18 (Edward's syndrome), or 21 (Down's syndrome) constitute an important indication for prenatal diagnosis, being the three autosomal trisomies found with significant frequency among live births.

For more than 25 years, the prenatal diagnosis of chromosomal abnormalities, based on full karyotyping of fetal 
cells from amniotic fluid (AF), has been the gold standard. However, in vitro culture requires sufficient cells, great technical expertise and time consuming manual procedures. Its main limit is the significant delay in providing the diagnosis (about 10-20 days), which leads to an inevitable and important anxiety period for the parents [1].

More recently, several methods based on fluorescence in situ hybridisation (FISH) or semi-quantitative fluorescent PCR (QF-PCR) of short tandem repeats (STRs) have been developed for rapid detection of aneuploidies in high-risk pregnancies, allowing a prenatal diagnosis of chromosomal abnormalities within 24-48 h. Introduced in the late 1980s, FISH analysis of uncultured interphase fetal cells with commercially available multicolour specific probes is presently routinely performed [2]. Although fast and reliable, the prenatal detection of aneuploidies by FISH remains expensive and its use is mainly restricted to pregnancies with anomalies detected by ultrasonography. The use of QF-PCR of STR for fast detection of aneuploidies has been applied to trisomy 21 [3]. Since 1993, this molecular approach has been extensively used by several groups on a research basis [4-9] and the diagnosis of aneuploidies by QF-PCR of STR has now been validated as a reliable method applicable in laboratories $[10,11]$. However, replacement of full karyotypes with rapid testing for trisomies 13, 18, and 21 by PCR or FISH should result in substantial numbers of liveborn children with hitherto preventable mental or physical handicaps [12].

Amniotic fluid is a significant contributor to fetal health and constitutes a potential rich source of biomarkers for diagnosis of fetal disorders [13]. Particularly, genetic abnormalities such as trisomies may induce alterations of protein expression and/or content which may be useful for diagnosis of many pathologies. Proteomic studies of $\mathrm{AF}$ have recently been successfully used to detect premature rupture of membranes $[14,15]$, to diagnose intraamniotic infection [16-20] and Down syndrome [21-23].

To identify useful and relevant biomarkers for fetal aneuploidies in AF, we used a method based on initial protein fractionation by retenate chromatography on protein chip arrays followed by SELDI-TOF/MS. We examined aneuploidy-specific protein signatures in amniotic fluid of pregnancies at the $17^{\text {th }}$ week of gestation with trisomies 21,18 and 13 foetuses, compared to chromosomally normal ones using 3 chromatographic conditions.

\section{Results}

\section{Reproducibility}

In order to evaluate the variability of SELDI, we first tested the experimental reproducibility using a pool of normal $\mathrm{AF}$, spotted randomly onto each array together with the tested AF samples. The peaks generated for reproducibility purposes were obtained using the CM10, Q10, H50 and IMAC30-Cu chips. The coefficients of variation of 15 reliable peaks were calculated by average peak intensity values derived from 20 different runs. Acceptable average CVs of 10 and $17 \%$ were obtained for intra and inter-assay variability, respectively, which is consistent with previously reported studies of SELDI $[24,25]$.

\section{Representative biomarkers: Univariate analysis}

Twenty-eight AF samples corresponding to the training set (15 aneuploidie and 13 normal samples) were analysed using four different array surfaces. Trisomy 21 was diagnosed by standard cytogenetic methods in 9 cases, trisomy 18 in 4 cases, and trisomy 13 in 2 cases. Using the ProteinChip and Biomarkers Wizard software, a total of 208 protein peak clusters in a range of 2.5 to $50 \mathrm{kDa}$ were obtained from the training set: 52 with the CM10, 79 with the Q10 and 77 with the IMAC30-Cu arrays. The H50 array was not subjected to analysis due to the weak number of peaks detected in preliminary experiments. According to our first statistical criteria, we selected 40 (11, 16 and 13 for CM10, Q10 and IMAC30-Cu, respectively) of 208 protein peaks that were significantly differentially expressed between aneuploidie AF and control samples $(p<0.05)$. Among these 40 peaks, 12 of them were overexpressed and 28 of them underexpressed in aneuploidie AF as compared to the control samples. Diagnostic values of each of these 40 differentially expressed peaks were high, with an AUC of the receiver operator characteristic curve (AUC-ROC) ranging from 0.71 to 0.91 according to the different protein peaks. A representative example of 3 discriminating protein peaks are shown in Figure 1 and the mean intensity, the p-value and the AUC value of the 40 peaks were given in Table 1 .

\section{Representative Biomarkers: Multivariate Analysis}

A heat cluster map, indicating up and down regulation of possible biomarker candidates, was generated for a multivariate analysis of the samples in a training set. The heat cluster map generated represents all the possible biomarker peaks between 2.5 and $50 \mathrm{kDa}$, from all three protein chips, in which differences in expression were observed between normal and aneuploid amniotic fluids. On the basis of the colour pattern (red indicating up regulation and green indicating down regulation) generated, it is clear that differences exist between normal samples compared to the aneuploid samples (Figure 2A). Upon closer observation of the heat cluster map, it is apparent that 3 aneuploid samples ( 2 trisomies for chromosome 18 and one for chromosome 21) were misclustered and have more possible biomarkers in common with the normal samples as compared to the aneuploid samples. In addition to the heat cluster map, a second multivariate analysis was generated using a PCA diagram. The PCA allowed us to visualize the relationship between the normal and 
Table I: Forty statistically significant protein peaks are differentially expressed in normal and aneuploid AF samples

\begin{tabular}{|c|c|c|c|c|c|c|}
\hline \multirow[b]{2}{*}{$m / z^{(a)}$} & \multirow[b]{2}{*}{ Surface array } & \multirow[b]{2}{*}{$p$-value (b) } & \multirow[b]{2}{*}{ AUC (c) } & \multicolumn{2}{|c|}{ Peak intensity (d) } & \multirow[b]{2}{*}{ Fold Change } \\
\hline & & & & Normal & Aneuploidies & \\
\hline 6080 & CMIO & 0.00001 & 0.918 & 1.66 & 9.50 & 5.7 \\
\hline 2876 & CMIO & 0.0006 & 0.861 & 6.37 & 20.96 & 3.3 \\
\hline 15944 & IMAC & 0.0013 & 0.838 & 4.12 & 1.99 & 0.5 \\
\hline 3023 & CMIO & 0.0015 & 0.837 & 10.06 & 27.88 & 2.8 \\
\hline 7970 & IMAC & 0.0016 & 0.833 & 4.78 & 2.67 & 0.6 \\
\hline 6194 & CMIO & 0.003 & 0.817 & 1.55 & 9.75 & 6.3 \\
\hline 3903 & IMAC & 0.0037 & 0.810 & 7.85 & 2.90 & 0.4 \\
\hline 8455 & CMIO & 0.0065 & 0.793 & 38.28 & 26.92 & 0.7 \\
\hline 22214 & CMIO & 0.0065 & 0.793 & 0.30 & 0.16 & 0.5 \\
\hline 9626 & IMAC & 0.0068 & 0.790 & 5.19 & 3.01 & 0.6 \\
\hline 24720 & Q10 & 0.0079 & 0.781 & 0.58 & 0.48 & 0.8 \\
\hline 9467 & IMAC & 0.0105 & 0.776 & 6.05 & 4.02 & 0.7 \\
\hline 3173 & Q10 & 0.0118 & 0.768 & 4.64 & 2.04 & 0.4 \\
\hline 18977 & IMAC & 0.012 & 0.771 & 0.61 & 0.29 & 0.5 \\
\hline 4323 & Q10 & 0.0134 & 0.763 & 5.66 & 9.47 & 1.7 \\
\hline 5655 & Q10 & 0.0134 & 0.763 & 5.47 & 2.92 & 0.5 \\
\hline 14017 & IMAC & 0.0137 & 0.767 & 4.82 & 2.65 & 0.5 \\
\hline 3184 & CMIO & 0.0151 & 0.764 & 2.93 & 8.41 & 2.9 \\
\hline 3435 & IMAC & 0.0157 & 0.762 & 2.66 & 9.04 & 3.4 \\
\hline 8660 & CMIO & 0.0172 & 0.760 & 4.95 & 3.00 & 0.6 \\
\hline 9276 & IMAC & 0.0178 & 0.757 & 1.90 & 4.11 & 2.2 \\
\hline 12289 & IMAC & 0.0178 & 0.757 & 4.97 & 3.33 & 0.7 \\
\hline 15056 & Q10 & 0.0194 & 0.750 & 0.78 & 1.31 & 1.7 \\
\hline 3383 & CMIO & 0.0196 & 0.755 & 7.24 & $|2.7|$ & 1.8 \\
\hline$|376|$ & IMAC & 0.0202 & 0.752 & 6.15 & 4.10 & 0.7 \\
\hline 7655 & Q10 & 0.0245 & $0.74 I$ & 4.52 & 6.56 & 1.5 \\
\hline 14014 & Q10 & 0.0245 & $0.74 I$ & 4.56 & 2.72 & 0.6 \\
\hline 11670 & CMIO & 0.0251 & 0.744 & 3.19 & 1.92 & 0.6 \\
\hline 4954 & IMAC & 0.0259 & 0.743 & 14.73 & 10.19 & 0.7 \\
\hline 7007 & Q10 & 0.0275 & 0.737 & 3.85 & 1.98 & 0.5 \\
\hline 6892 & Q10 & 0.0308 & 0.732 & 4.34 & 3.26 & 0.8 \\
\hline 8203 & Q10 & 0.0308 & 0.732 & 5.80 & 3.45 & 0.6 \\
\hline 9159 & Q10 & 0.0308 & 0.732 & 9.03 & 7.82 & 0.9 \\
\hline 11314 & Q10 & 0.0344 & 0.728 & 6.90 & 4.10 & 0.6 \\
\hline 8574 & IMAC & 0.0367 & 0.729 & 12.48 & 7.55 & 0.6 \\
\hline 4519 & Q10 & 0.0472 & 0.714 & $\mathrm{I} .44$ & 2.27 & 1.6 \\
\hline 4901 & Q10 & 0.0472 & 0.714 & 3.61 & 2.25 & 0.6 \\
\hline 13809 & Q10 & 0.0472 & 0.714 & 4.20 & 2.73 & 0.6 \\
\hline 49297 & Q10 & 0.0472 & 0.714 & 0.21 & 0.16 & 0.8 \\
\hline 11303 & CMIO & 0.0499 & 0.716 & 2.62 & 1.90 & 0.7 \\
\hline
\end{tabular}

a) $\mathrm{m} / \mathrm{z}$ : mass/charge ratio of the protein peak.

b) P-values were calculated using parametric Mann-Whitney test.

c) AUC (area under the ROC curve) were calculated using normal amniotic fluids as reference.

d) Averages of peak intensities.

aneuploid samples in a three-dimensional view based on all the potential biomarkers identified. Blue circles represent normal samples in contrast to the red circles, which represent aneuploid samples. Based on the PCA diagram, we could conclude that the same 3 amniotic and 3 normal samples are still misclassified (Figure 2B). Markers chosen as representatives had a $p<0.05$ indicating their significance.
To construct a multivariate classifier for aneuploidies, we used the 208 protein peaks obtained by SELDI analysis to train a SVM classification algorithm taking into account biomarker inter-correlations. SVM is a supervised learning technique that constructs an optimal separating hyperplane from the training set with an aim of classifying the test set [26-28]. It achieved an overall classification accuracy of $92.86 \%$, sensitivity of $93.33 \%$, and specificity of $92.31 \%$ in distinguishing normal samples from aneu- 

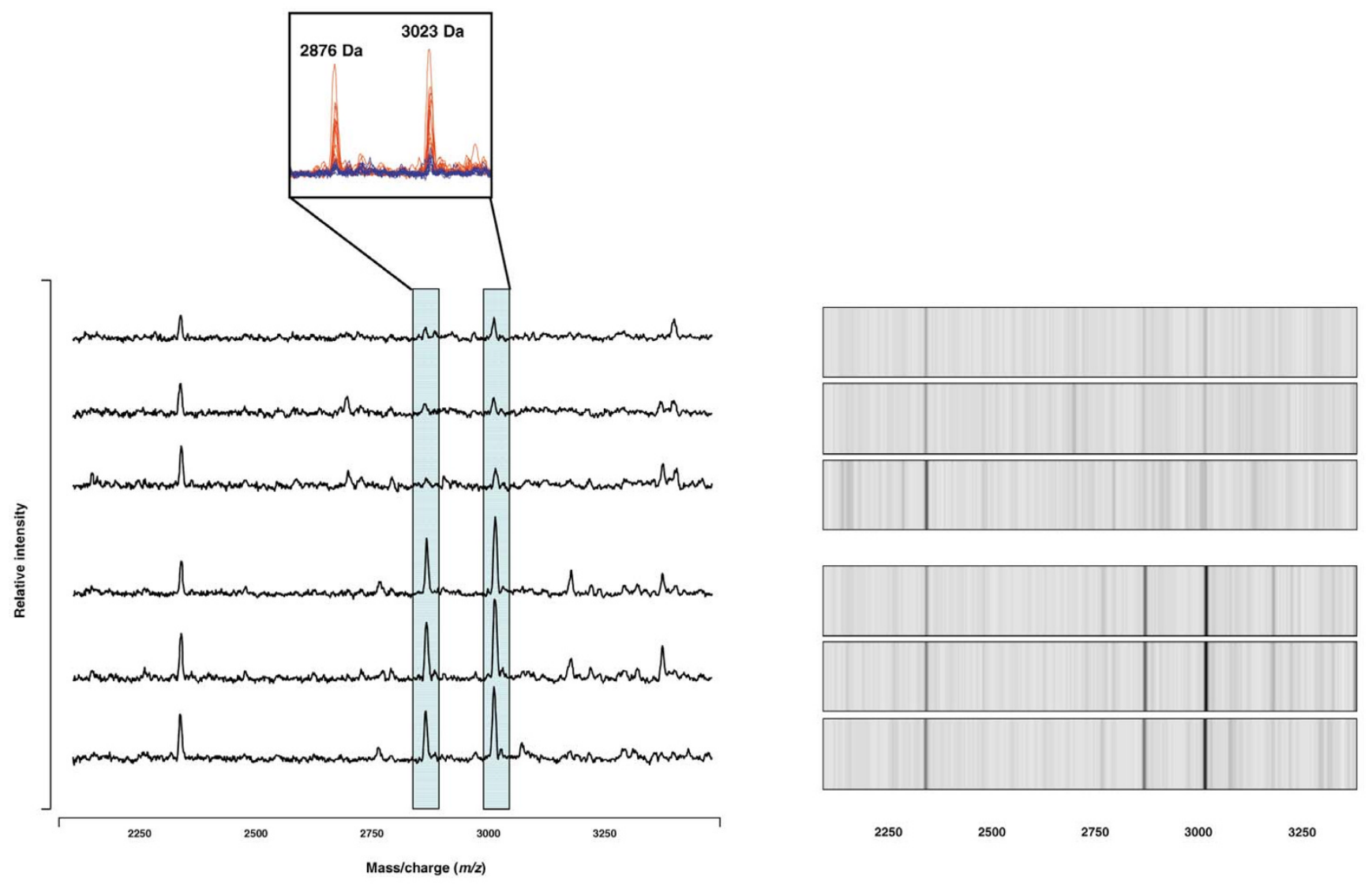

Figure I

Representative SELDI-TOF spectra (left panel) and gel (right panel) views of selected biomarkers obtained from normal and aneuploid AF samples. For both protein peaks, the data of three normal karyotypes samples (N, upper panel) and three aneuploidy karyotypes samples (A, lower panel) are shown. Frames indicate the positions of two peaks at 2876 and $3023 \mathrm{Da}$, respectively, both overexpressed in aneuploid samples. Overlay of protein mass spectra is represented in the upper box. Protein mass spectra obtained from aneuploid (red) and normal (blue) AF are superimposed.

ploid samples. To construct a multivariate classifier, we also performed a preselection step to allow an optimal identification of differentially expressed peaks. Logistic regression was used to construct a multiprotein classifier composed of two protein peaks (CM10, $6194 \mathrm{kDa}-$ and $\mathrm{Q} 10,3173 \mathrm{kDa})$. The composite index yielded higher AUC value (0.928) than the individual protein peaks (0.817 and 0.768). Table 2 indicates the mean performance of both classification methods. In order to validate our classifiers, we next performed an independent validation test on $24 \mathrm{AF}$ samples (12 normal and 12 aneuploid samples). SVM algorithm was used to classify the test set. Trisomy 21 was diagnosed by standard cytogenetic methods in 8 cases, trisomy 18 in 3 cases, and trisomy 13 in 1 case. Results indicated that overall classification accuracies were maintained in the validation phase with $87.5 \%$ (sensitivity $83.33 \%$, specificity $83.33 \%$ ) and $91.67 \%$ (sensitivity $83.33 \%$, specificity $100 \%$ ) for SVM classification and logistic regression indexes, respectively. Consid- ering an estimated prevalence of aneuploidies in the general population of $1 / 800$ [29], we evaluated the PPV and the NPV for both classifiers (Table 2).

\section{Discussion}

With the development of obstetric ultrasound examinations for prenatal care, fetal anomalies are often found without the objective of diagnosis [30]. These findings do not allow identification of a specific chromosome region as a target for prenatal diagnosis. Although microarray analyses have been used to identify many molecular events and to analyse variations in gene expression associated with aneuploidies [31-33], the level of mRNA expression does not systematically reflect the proteome in a cell. Indeed, translation of mRNA into proteins depends on several post-transcriptional and post-translational events (glycosylation, phosphorylation, acetylation, etc.). Hence, direct measurement of protein expression may determine cell dysfunction more effectively. Proteome 
A
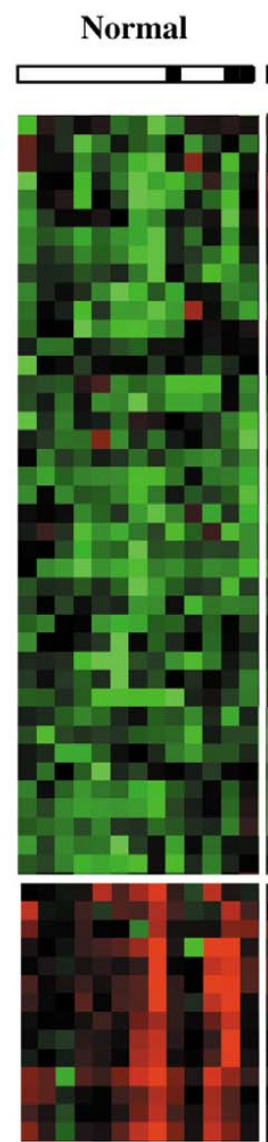

Aneuploid

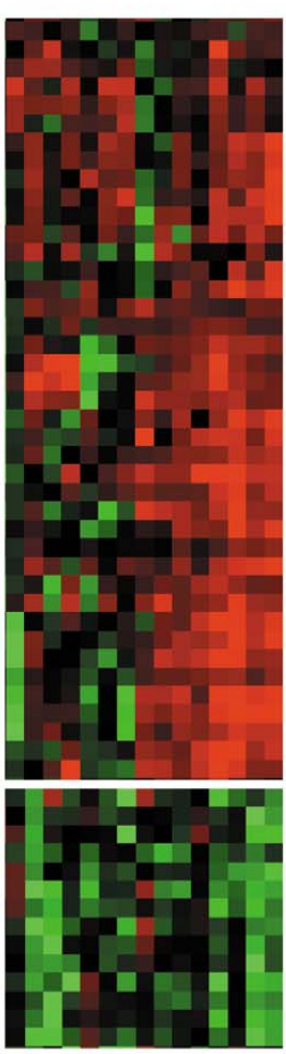

B

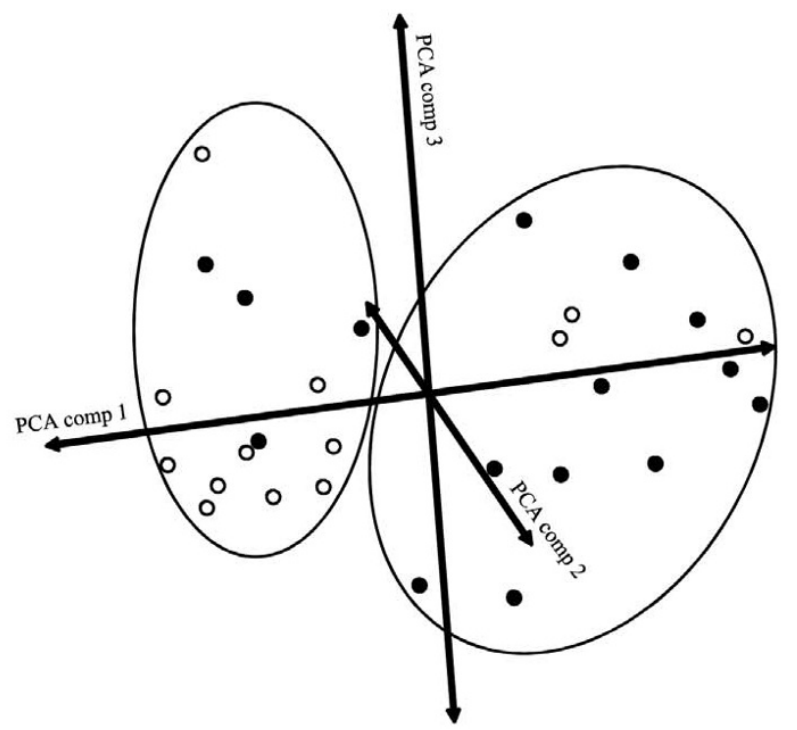

Figure 2

Heat cluster map and principle component analysis (PCA) of aneuploidie amniotic fluid and normal samples. All 208 protein peaks from 2.5 to $50 \mathrm{kDa}$ mass range and 3 different surface arrays were pooled to generate a heat cluster map (A) and PCA diagram (B). The PCA diagram illustrates the segregated samples based on normal (white circles) and aneuploidie (black circles) samples.

analysis is based on the combination of three technologies: a resolutive method for separating proteins as a function of different physico-chemical criteria (mass, pI, hydrophobicity, etc.), mass spectrometry (MS) and bioinformatic tools. It is therefore possible to identify proteins from MS data and quantitatively analyse their expression simultaneously. Bi-dimensional gel electrophoresis coupled with MALDI-TOF MS (Matrix Assisted Laser Desorption Ionization - Time of Flight) remains the most powerful resolutive method to separate complex mixtures

Table 2: Diagnostic performance of classifiers

\begin{tabular}{|c|c|c|c|c|c|c|c|}
\hline \multirow[b]{2}{*}{ Model } & \multirow[b]{2}{*}{ Accuracy } & \multirow[b]{2}{*}{ Sensitivity } & \multirow[b]{2}{*}{ Specificity } & \multicolumn{2}{|c|}{ Tested population } & \multicolumn{2}{|c|}{ General population } \\
\hline & & & & PPV & NPV & PPV & NPV \\
\hline \multicolumn{8}{|l|}{ SVM multiprotein index } \\
\hline Learning population & 92.86 & 93.33 & 92.31 & 93.33 & 92.31 & 1.50 & 99.99 \\
\hline Testing population & 87.50 & 83.33 & 83.33 & 83.33 & 83.33 & 0.62 & 99.97 \\
\hline \multicolumn{8}{|c|}{ Logistic regression multiprotein index } \\
\hline Learning population & 96.43 & 93.33 & 100.00 & 100.00 & 92.86 & 100.00 & 99.99 \\
\hline Testing population & 91.67 & 83.33 & 100.00 & 100.00 & 87.71 & 100.00 & 99.98 \\
\hline
\end{tabular}

Positive Predictive Value (PPV) and Negative Predictive Value (NPV) were estimated for the tested population and for the general population (with a prevalence of $\mathrm{I} / 800)$. 
of proteins and to compare variations of protein expression in a pair of samples, such as normal versus tumour. The proteins of interest are identified by their peptide mass fingerprints, obtained after trypsin digestion in gel. This approach has been used in several studies since 2004 to identify potential biomarkers in amniotic samples for detection of premature rupture of membranes [14] and trisomy $21[22,34]$. Although bi-dimensional gel electrophoresis has proved effective in many fields, its use in clinical proteomics is limited. Indeed, it has a labourintensive and time-consuming nature rendering analysis of more than ten samples impossible. Therefore, it is only of limited value at the condition when tested individuals may elicit significant biological variations, such as those in multiple normal tissues from the same organ obtained from a group of normal individuals or those in different tumours of the same type of cancer but derived from different patients.

Recently, progresses in nanotechnologies based on liquid or surface-affinity chromatography have generated new broadband proteomic analysis techniques for application to diagnosis of human diseases. SELDI-TOF combines surface-affinity chromatography and mass spectrometry. It separates and detects peptide and protein peaks from various biological samples such as amniotic fluid, LCR, serum or tissue. Using the automated clinical proteomic method, hundreds of samples can be analysed within a short period of time allowing statistical analyses to detect significant differences between two groups of samples beyond the presence of individuals' biological variations [35]. SELDI-TOF has been previously used to detect aneuploidies in amniotic fluid $[21,23]$. Bush et al. described a clustering algorithm based on protein profiles obtained from H50 and SAX2 chip surfaces. Wang et al proposed a two-step proteomic analysis model based on a C18 purification set followed by a weak cation exchange. Both studies presented their classification method but did not clearly indicate discriminatory protein peak molecular weights, rendering an independent validation study not realizable. In our study, we have identified, using SELDITOF, the MS-generated proteomics profiles from 52 uncultured amniotic fluids to be able to distinguish normal foetuses from those with abnormal karyotypes. We found in an univariate analysis 40 peaks as potential biomarkers, of which 12 were overexpressed and 28 underexpressed, in aneuploid $\mathrm{AF}$ as compared to the control samples. All were considered statistically significant ( $p$ $<0.05$ ) and AUC values were correct, proving the validity of their accuracy. The most important steps in proteomic studies were the differential and statistical analysis of all data from the spectra. To analyse our data, we searched for a combination of methods that could reliably detect aneuploidies in a high-risk group of women. Since there is no "gold-standard" method for classification of mass spec- trometry data, we were interested in testing the validity and robustness of our methods. Using a SVM classification algorithm, we observed a classification accuracy of $92.9 \%$ with a sensitivity of $93.3 \%$, and specificity of $92.3 \%$. Since one of the challenges of SELDI data is to reduce the high-dimension of the spectra, we also extracted combination of markers from all the 208 protein peaks by logistic regression. This analysis identified combination of two protein peaks with an AUC of 0.928, a classification accuracy of $96.4 \%$, a sensitivity of $93.3 \%$ and a specificity of $100 \%$. Importantly, these values remained high in an independent validation set proving the robustness of these methods. Considering the sensitivity and specificity of our classifiers and the expected prevalence of aneuploidies in the general population, one can expect an extrapolated PPV of $0.4 \%$ and a NPV of $99.99 \%$ for the SVM classifier index, and a PPV of $100 \%$ and a NPV of $99.98 \%$ for the logistic regression classifier index. Thus, our proteomic classifiers could be more particularly used to rapidly screen, within two hours, for aneuploidies in a high-risk population in whom amniocentesis is indicated and when the diagnosis is urgently need. Due to the relatively high sensitivity and the perfect NPV of the test, we minimized the risk of missing an affected pregnancy. However, clinical trials with more samples are needed to verify the interest of this rapid detection by proteomic analysis.

The discriminating proteomic profiling model used in this study may show some limits. In particular, some aneuploid samples were misclassified (two trisomies 18 and one trisomy 21). The discrepancy between the cytogenetic and the molecular results may be explained by the fact that we analysed AF samples derived from various abnormal karyotypes as a group. In addition, we cannot exclude some sample contaminations with maternal cells. It would be interesting to discard all amniotic fluids suspected of blood cell contamination (determined by microscopic examination for red blood cells). This should allow the reallocation of some of these individuals into the correct group. Other limitation is that we analyzed AF samples from different aneuploidies as a group. Then, whether we are unable to specify trisomy 21,18 or 13 markers individually, we can detect rapidly various types of aneuploidies in one experiment, extending the potential of clinical application. Increasing number of samples in further studies should allow to individualise markers for specific trisomies detection.

We are convinced that, for the moment, none of the different proteomic approaches will replace chromosome analysis and karyotyping on cultured amniocytes [12]. However, a major drawback of this procedure is the necessity for viable cells to culture for prenatal diagnosis, which may take up to 2 weeks. Prenatal diagnosis based on 
amplification of STR detection and amplification on uncultured amniotic cells has proved reliable, avoiding the need to culture cells and reducing the time required for a diagnosis. However, this technique is time-consuming and requires intact cells. Our proteomic assay was designed for a rapid detection of common trisomies of chromosome 13, 18 and 21, focusing on high-risk pregnancies with anomalies detected by ultrasonography, as an alternative to FISH or PCR quantitation assay. Our results should be considered as screening or preliminary tests of aneuploidies in high-risk pregnancies that should be confirmed by cytogenetic analysis. In addition, this proteomic method allows further research to be conducted in this area, in particular, in serum samples of women with normal and aneuploidy fetuses for non-invasive prenatal diagnosis.

\section{Conclusion}

In conclusion, this report describes a proteomic approach combining ProteinChip technology and rule-based analysis that allow a screening for fetal aneuploidies with good accuracies. The assay could be used as an adjunct for traditional cytogenetic analysis as proposed by PCR quantitation array or FISH analysis. This preliminary study supports the view that SELDI-TOF is a valuable tool to identify biomarkers for aneuploidies diseases in amniotic fluid but also in serum.

\section{Methods}

\section{Supernatant specimens of amniotic fluid}

A total of 52 pregnant women underwent amniocentesis for prenatal chromosome analysis between gestational weeks 14 and 17 . These women were referred to the prenatal diagnosis unit of the university hospitals of Clermont-Ferrand and Montpellier. The referral criteria were maternal age ( 38 years which is the French cut-off age for free-of-charge karyotyping), positive biochemical screening for Down syndrome, abnormal fetal ultrasonic scan, positive family history of chromosomal rearrangement, or parental anxiety. Ethical approval for the study was obtained under the assumption that results were not reported to the referring clinicians. Through the transabdominal approach, about $20 \mathrm{ml}$ of AF was tapped from each patient. Conventional chromosome analyses were carried out for each sample. Two ml of AF were used for the proteomic study. Amniotic cells were collected by centrifugation at $1500 \mathrm{rpm}$ for $5 \mathrm{~min}$. After removing the supernatant, cells are frozen at $-80^{\circ} \mathrm{C}$ until analysis. Before proteomic analysis, cells were lysed in $50 \mathrm{mM}$ Tris pH 7.5, $100 \mathrm{mM} \mathrm{NaCl}, 5 \mathrm{mM}$ EDTA, 0.5\% Triton X100 and $0.5 \%$ CHAPS. Protein concentration was measured using the EZQ Protein quantitation kit (Molecular Probes) according to the manufacturer's protocol. From the 52 samples, training and testing populations were randomly done.

\section{Proteomic analysis}

Each AF samples were randomly applied on four different ProteinChip array surfaces (Ciphergen Biosystem, Inc) in a 96-well format: hydrophobic (H50), cation-exchange (CM10), anion-exchange (Q10) and metal binding (IMAC30-Cu). IMAC arrays were pre-treated twice with 50 $\mu \mathrm{L} 100 \mathrm{mM} \mathrm{CuSO} 4$ on a shaker for $5 \mathrm{~min}$, followed by two washes with $100 \mu \mathrm{L}$ water. ProteinChip arrays were equilibrated twice with $100 \mu \mathrm{L}$ binding buffer on a shaker for $5 \mathrm{~min}$ and $50 \mu \mathrm{L}$ binding buffer was added to the surface spots. Five $\mu \mathrm{g}$ of each sample was added to the binding buffer and the arrays were incubated for $30 \mathrm{~min}$ on a shaker. Arrays were washed three times with $100 \mu \mathrm{L}$ binding buffer, followed by a final water wash. For the H50 arrays the final wash was in binding buffer. Arrays were removed from the bioprocessor, allowed to air dry and 1 $\mu \mathrm{L}$ of $50 \%$ SPA was applied twice to the spots. Binding buffers used for the different arrays were $10 \% \mathrm{CH} 3 \mathrm{CN}$, $0.1 \%$ TFA for H50; $100 \mathrm{mM} \mathrm{NaAC} \mathrm{pH} 4.0$ for CM10; 100 $\mathrm{mM}$ Tris-HCl $\mathrm{pH} 9.0$ for Q10; and $100 \mathrm{mM}$ phosphate buffer pH 7.0, $500 \mathrm{mM} \mathrm{NaCl}$ for IMAC30-Cu. Finally, arrays were analysed on a PBS-IIc ProteinChip Reader. Data were averaged over 200 transients for each spot and were performed in the range of 2.5 to $50 \mathrm{kDa}$. Training and testing phases were run in independent experiments.

\section{Reproducibility}

Mass detection accuracy of PBSIIc was calibrated externally by using the All-in-1 protein II molecular mass standards (Ciphergen Biosystems). Reproducibility was estimated using a control sample which was randomly spotted on each chip to measure the variability of fractionation, on-chip spotting, and data acquisition. Intensity values for the selected peaks were used to calculate coefficients of variation (CV). The reproducibility analysis was performed for all surface conditions and spectra were collected following the experimental protocols described above.

\section{Peak detection}

Analysis of peaks was performed using the ProteinChip and Biomarker Wizard software from Ciphergen Biosystem. Spectra were background subtracted and the peak intensities were normalized to the total ion current of $\mathrm{m} /$ $z$ between 2.5 and $50 \mathrm{kDa}$. Automatic peak detection was performed with the following settings: i) signal-to-noise ratio at 4 for the first pass and 2 for the second pass, ii) minimal peak threshold at $15 \%$ of all spectra, iii) cluster mass window at $0.5 \%$ of mass. The resulting CSV file containing absolute intensity and $\mathrm{m} / \mathrm{z}$ ratio was exported into Microsoft Excel (Microsoft, Redmond) for subsequent analysis. 


\section{Statistical data analysis}

Univariate statistical analysis of SELDI-TOF peak masses and relative intensity values was conducted with the nonparametric Mann-Whitney U-test. Differentially expressed proteins were defined with a $p$-value $<0.05$. Peak intensity data were then preprocessed before multivariate statistical analysis using logarithmic transformation. Data were analysed using various statistical algorithms such as hierarchical clustering, principal component analysis (PCA) and support vector machine (SVM) analysis, implemented in the MultiExperiment Viewer software (Mev, version 4) [36]. Hierarchical clustering and PCA were not used as predictive tools, but purely as a mean to understand and visualize the data structures being analysed. All $\mathrm{m} / \mathrm{z}$ values were subject to average-linkage hierarchical clustering, using Pearson correlation as a distance metric. The peaks and samples were organized by creating dendrograms. We also performed dimension reduction using PCA, which converted higher-dimensional space spanned by differential peaks into less-redundant and lower-dimensional space of several principal components. A class prediction model was defined from the training samples using SVM. SVM was chosen because this learning scheme was known to perform well in the challenging situation in which the number of samples in the data set is not large compared with the number of attributes. In our case, the attributes were the peaks. SVM found the maximum margin hyperplane, which was the hyperplane separating the two classes of samples in a n-dimensional space while maximizing the distance between the hyperplane and the closest training point. On the other hand, logistic regression was used for peak selection and to construct a multiprotein classifier from all the 208 protein peaks. To maximize the use of our relatively small data set, we have assessed the performance of our class prediction models with an external validation scheme. The classifier was thus used to predict the class validation samples.

\section{Competing interests}

The author(s) declare that they have no competing interests.

\section{Authors' contributions}

AM participated to the design of the experiment, performed the proteomic analysis and drafted the manuscript.

CD and VB carried out the SELDI-TOF analysis.

AM and NM carried out the statistical analysis.

TM was the head of the laboratory

JS coordinated the study and wrote the final version of the manuscript.
All authors read and approved the final manuscript.

\section{Acknowledgements}

We thank Prof. P. Boulot from the Department of Obstetrics and Gynaecology, Arnaud de Villeneuve Hospital of Montpellier; Dr P. Benazech from the Clémenville Clinical Centre of Montpellier; and Prof. D. Lemery from the Department of Gynaecology, Hotel Dieu Hospital from Clermont-Ferrand for their help in the acquisition of the amniotic fluid samples. We thank also Nicolas Molinari from IURC to perform some proteomic analyses.

\section{References}

I. Hewison J, Nixon J, Fountain J, Hawkins K, Jones CR, Mason G, Morley S, Thornton JG: A randomised trial of two methods of issuing prenatal test results: the ARIA (Amniocentesis Results: Investigation of Anxiety) trial. Bjog 2007, I I 4(4):462-468.

2. Feldman B, Ebrahim SA, Hazan SL, Gyi K, Johnson MP, Johnson A, Evans MI: Routine prenatal diagnosis of aneuploidy by FISH studies in high-risk pregnancies. Am J Med Genet 2000, 90(3):233-238.

3. Mansfield ES: Diagnosis of Down syndrome and other aneuploidies using quantitative polymerase chain reaction and small tandem repeat polymorphisms. Hum Mol Genet 1993 , 2(1):43-50.

4. Rahil H, Solassol J, Philippe C, Lefort G, Jonveaux P: Rapid detection of common autosomal aneuploidies by quantitative fluorescent PCR on uncultured amniocytes. Eur J Hum Genet 2002, IO(8):462-466.

5. Ogilvie CM, Donaghue C, Fox SP, Docherty Z, Mann K: Rapid prenatal diagnosis of aneuploidy using quantitative fluorescence-PCR (QF-PCR). I Histochem Cytochem 2005, 53(3):285-288.

6. Donaghue C, Mann K, Docherty Z, Ogilvie CM: Detection of mosaicism for primary trisomies in prenatal samples by $Q F$ PCR and karyotype analysis. Prenat Diagn 2005, 25(I):65-72.

7. Mann K, Donaghue C, Fox SP, Docherty Z, Ogilvie CM: Strategies for the rapid prenatal diagnosis of chromosome aneuploidy. Eur J Hum Genet 2004, I 2(I I):907-9I5.

8. Pertl B, Kopp S, Kroisel PM, Tului L, Brambati B, Adinolfi M: Rapid detection of chromosome aneuploidies by quantitative fluorescence PCR: first application on 247 chorionic villus samples. J Med Genet 1999, 36(4):300-303.

9. Waters JJ, Mann K, Grimsley L, Ogilvie CM, Donaghue C, Staples L, Hills A, Adams T, Wilson C: Complete discrepancy between QF-PCR analysis of uncultured villi and karyotyping of cultured cells in the prenatal diagnosis of trisomy 21 in three CVS. Prenat Diagn 2007, 27(4):332-339.

10. Brown L, Abigania M, Warburton D, Brown S: Validation of QFPCR for prenatal aneuploidy screening in the United States. Prenat Diagn 2006, 26(II): 1068-1074.

II. Mann K, Fox SP, Abbs SJ, Yau SC, Scriven PN, Docherty Z, Ogilvie CM: Development and implementation of a new rapid aneuploidy diagnostic service within the UK National Health Service and implications for the future of prenatal diagnosis. Lancet 200I, 358(9287): I057-106I.

12. Caine A, Maltby AE, Parkin CA, Waters J], Crolla JA: Prenatal detection of Down's syndrome by rapid aneuploidy testing for chromosomes 13, 18, and 21 by FISH or PCR without a full karyotype: a cytogenetic risk assessment. Lancet 2005, 366(9480): $123-128$.

13. Michaels JE, Dasari S, Pereira L, Reddy AP, Lapidus JA, Lu X, Jacob T, Thomas A, Rodland M, Roberts CT Jr., Gravett MG, Nagalla SR: Comprehensive proteomic analysis of the human amniotic fluid proteome: gestational age-dependent changes. J Proteome Res 2007, 6(4): I277-I 285.

14. Vuadens F, Benay C, Crettaz D, Gallot D, Sapin V, Schneider P, Bienvenut WV, Lemery D, Quadroni M, Dastugue B, Tissot JD: Identification of biologic markers of the premature rupture of fetal membranes: proteomic approach. Proteomics 2003, 3(8): $|52|-\mid 525$.

15. Michel PE, Crettaz D, Morier P, Heller M, Gallot D, Tissot JD, Reymond F, Rossier JS: Proteome analysis of human plasma and amniotic fluid by Off-Gel isoelectric focusing followed by nano-LC-MS/MS. Electrophoresis 2006, 27(5-6): I 169-I I8I. 
16. Buhimschi CS, Buhimschi IA, Abdel-Razeq S, Rosenberg VA, Thung SF, Zhao G, Wang E, Bhandari V: Proteomic biomarkers of intraamniotic inflammation: relationship with funisitis and earlyonset sepsis in the premature neonate. Pediatr Res 2007, 6 I(3):318-324.

17. Gravett MG, Novy MJ, Rosenfeld RG, Reddy AP, Jacob T, Turner M, McCormack A, Lapidus JA, Hitti J, Eschenbach DA, Roberts CT Jr., Nagalla SR: Diagnosis of intra-amniotic infection by proteomic profiling and identification of novel biomarkers. Jama 2004, 292(4):462-469.

18. Gravett MG, Thomas A, Schneider KA, Reddy AP, Dasari S, Jacob T, Lu X, Rodland M, Pereira L, Sadowsky DW, Roberts CT Jr., Novy MJ, Nagalla SR: Proteomic analysis of cervical-vaginal fluid: identification of novel biomarkers for detection of intra-amniotic infection. J Proteome Res 2007, 6(I):89-96.

19. Klein LL, Freitag BC, Gibbs RS, Reddy AP, Nagalla SR, Gravett MG: Detection of intra-amniotic infection in a rabbit model by proteomics-based amniotic fluid analysis. Am J Obstet Gynecol 2005, I 93(4): I 302-1306.

20. Pettker CM, Buhimschi IA, Magloire LK, Sfakianaki AK, Hamar BD, Buhimschi CS: Value of placental microbial evaluation in diagnosing intra-amniotic infection. Obstet Gynecol 2007 I 09(3):739-749.

21. Busch A, Michel S, Hoppe C, Driesch D, Claussen U, von Eggeling F: Proteome analysis of maternal serum samples for trisomy 2 I pregnancies using ProteinChip arrays and bioinformatics. J Histochem Cytochem 2005, 53(3):34I-343.

22. Tsangaris GT, Karamessinis P, Kolialexi A, Garbis SD, Antsaklis A, Mavrou A, Fountoulakis M: Proteomic analysis of amniotic fluid in pregnancies with Down syndrome. Proteomics 2006, 6(I 5):4410-4419.

23. Wang TH, Chang YL, Peng HH, Wang ST, Lu HW, Teng SH, Chang SD, Wang HS: Rapid detection of fetal aneuploidy using proteomics approaches on amniotic fluid supernatant. Prenat Diagn 2005, 25(7):559-566.

24. Albrethsen J: Reproducibility in protein profiling by MALDITOF mass spectrometry. Clin Chem 2007, 53(5):852-858.

25. Semmes OJ, Feng Z, Adam BL, Banez LL, Bigbee WL, Campos D, Cazares LH, Chan DW, Grizzle WE, Izbicka E, Kagan J, Malik G, McLerran D, Moul JW, Partin A, Prasanna P, Rosenzweig J, Sokoll LJ, Srivastava S, Srivastava S, Thompson I, Welsh MJ, White N, Winget M, Yasui Y, Zhang Z, Zhu L: Evaluation of serum protein profiling by surface-enhanced laser desorption/ionization time-offlight mass spectrometry for the detection of prostate cancer: I. Assessment of platform reproducibility. Clin Chem 2005, 5 I(I): I02-II2.

26. Girosi F: An Equivalence Between Sparse Approximation and Support Vector Machines. Neural Comput 1998, I 0(6): | $455-1480$.

27. Lee M: Analysis of Microarray Gene Expression Data. Boston: Kluwer Academic Publishers 2004.

28. Li L, Tang H, Wu Z, Gong J, Gruidl M, Zou J, Tockman M, Clark RA: Data mining techniques for cancer detection using serum proteomic profiling. Artif Intell Med 2004, 32(2):7I-83.

29. European Registration of Gongenital Anomalies (EUROCAT): I5 years of surveillance of congenital anomalies in Europe Report 7. Bruxelles, Scientific Institute of Public Health - Louis Pasteur; 1997.

30. Schmidt $\mathrm{P}$, Rom J, Maul $\mathrm{H}$, Vaske B, Hillemanns $\mathrm{P}$, Scharf $A$ Advanced first trimester screening (AFS): an improved test strategy for the individual risk assessment of fetal aneuploidies and malformations. Arch Gynecol Obstet 2007, 276(2): I59-166.

31. Chung IH, Lee SH, Lee KW, Park SH, Cha KY, Kim NS, Yoo HS, Kim YS, Lee S: Gene expression analysis of cultured amniotic fluid cell with Down syndrome by DNA microarray. J Korean Med Sci 2005, 20(I):82-87.

32. Larrabee PB, Johnson KL, Pestova E, Lucas M, Wilber K, LeShane ES, Tantravahi U, Cowan JM, Bianchi DW: Microarray analysis of cellfree fetal DNA in amniotic fluid: a prenatal molecular karyotype. Am J Hum Genet 2004, 75(3):485-49I.

33. Miura S, Miura K, Masuzaki H, Miyake N, Yoshiura K, Sosonkina N, Harada N, Shimokawa O, Nakayama D, Yoshimura S, Matsumoto N, Niikawa $\mathrm{N}$, Ishimaru $\mathrm{T}$ : Microarray comparative genomic hybridization (CGH)-based prenatal diagnosis for chromo- some abnormalities using cell-free fetal DNA in amniotic fluid. J Hum Genet 2006, 5 I (5):4I2-4I7.

34. Tsangaris GT, Kolialexi A, Karamessinis PM, Anagnostopoulos AK, Antsaklis A, Fountoulakis M, Mavrou A: The normal human amniotic fluid supernatant proteome. In Vivo 2006, 20(4):479-490.

35. Solassol J, Jacot W, Lhermitte L, Boulle N, Maudelonde T, Mange A: Clinical proteomics and mass spectrometry profiling for cancer detection. Expert Rev Proteomics 2006, 3(3):3 I I-320.

36. Saeed Al, Sharov V, White J, Li J, Liang W, Bhagabati N, Braisted J, Klapa M, Currier T, Thiagarajan M, Sturn A, Snuffin M, Rezantsev A, Popov D, Ryltsov A, Kostukovich E, Borisovsky I, Liu Z, Vinsavich A, Trush V, Quackenbush J: TM4: a free, open-source system for microarray data management and analysis. Biotechniques 2003, 34(2):374-378.

Publish with Bio Med Central and every scientist can read your work free of charge

"BioMed Central will be the most significant development for disseminating the results of biomedical research in our lifetime. "

Sir Paul Nurse, Cancer Research UK

Your research papers will be:

- available free of charge to the entire biomedical community

- peer reviewed and published immediately upon acceptance

- cited in PubMed and archived on PubMed Central

- yours - you keep the copyright 